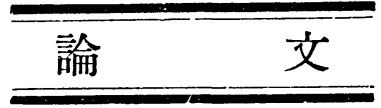

\title{
各種酸類による $\mathrm{Ti}$ 腐強面の電子迴折的研究 $(\text { 第 } 1 \text { 報 })^{*}$
}

\author{
小川四郎**渡邊傳 次郎**
}

Shiro Ogawa and Denjiro Watanabe: Titanium Surface attacked by Several Acids (I). titanium has an excellent oxidation-and corrosion-resistance. We have exanined, by the electron diffraction method, surface films formed on titanium attacked by several acids at various conditions. Diffraction patterns obtained from the surfaces attacked by $\mathrm{HF}, \mathrm{HCl}, \mathrm{H}_{2} \mathrm{SO}_{4}$ and $\mathrm{H}_{3} \mathrm{PO}_{4}$ showed rings due to f.c.c. lattice which may be deduced to occur from $\mathrm{TiH}_{\ldots}$. When these specimens were heated in vacuum at $450 \sim 800^{\circ}$ for a few hours, the rings due to titanium and to $\mathrm{TiC}$ (NaCl-type) appeared. From this fact, we have confirmed that $\mathrm{TiH}_{2}$ formed on the titanium s irface is decomposed in vacuum at high temperatures, as Gulbransen et al pointed out. When the specimens treated in this way or rolled specimens were immersed in $\mathrm{HNO}_{3}$ at room temperature for $4 \sim 10$ days, just hexagonal diffraction rings due to titanium only were obtainel, and we started from these surfaces observations to further experiments. When the spe:imens were attacked by boiling $\mathrm{HNO}_{3}$ and aqua regia, the surface films consisted of $\mathrm{TiO}_{2}$ (anatase), but when attaciked by boiling $10 \% \mathrm{CrO}_{3}$-solution films of $\mathrm{Ti} \mathrm{O}_{2}$ (anatase+rutile) were found. The surfaces attacked by boiling $10 \% \mathrm{FeCl}_{3}$-solution for one hour gave many sharp Debye rings; however, the crystal strusture of this film has not bean determined at the prese.t stage.

(Received May 8, 1954)

\section{I. 緒論}

金庭チタン(六们稠密路厅， $a=2.92 \AA ， c=4.67 \mathrm{~A}^{(1)}$ )が

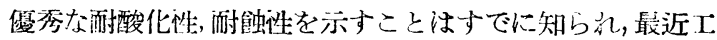

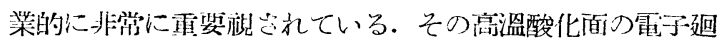
折的研究: Hi kman 怙よび Gulbransen(2)ならびに中 山(3)によつて詳しくなされており，表面被膜として Rutile 型 TiOnが形成さ礼て耐酸化性走示与ことが明ら

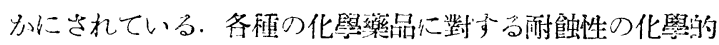

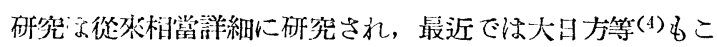
の研究众行つた。今までのところ耐玲性仁對する電于迴折

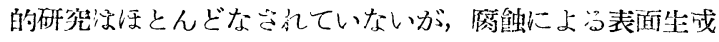

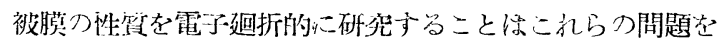

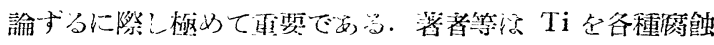

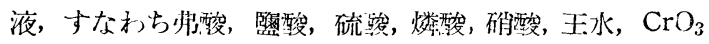
水溶液, $\mathrm{NaCl}$ 水溶液括よび $\mathrm{FeCl}_{3}$ 水溶液などに浸漬さ

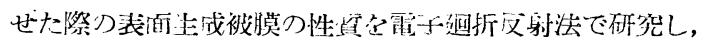

** 東北大學金碣材料研究所

* 1953 年 10 月本會仙敢大會汇酸裴.

(1) R. W. G. Wyckoff, Crystal Structures, I (1951)

(2) J. W. Hickman and E. A. Gulbransen. Analy, Chem., 20(1918), 158.

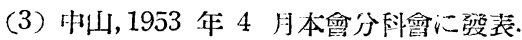

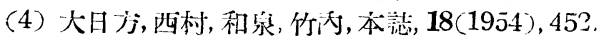

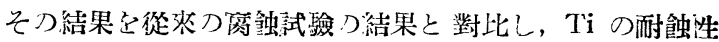
についてそつ大略莡明らかにした。

\section{II. 裝置および試料}

使周した電子迴折カメラ综日立裂作所製 ED-C 縱型カ メラで, カメラ距㒕は $309 \mathrm{~mm}$, 加速冠厴学約 $50 \mathrm{kV}$ で

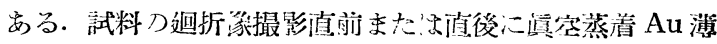
膜つ透過像炎撮影し，これ心上つて需子湶つ波長占決定し

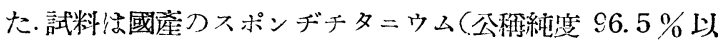

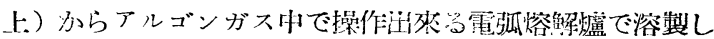

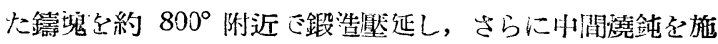

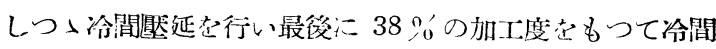
仕上壓延足行つた厚さ $0.5 \mathrm{~mm}$ の Ti 板で, 金研大日方

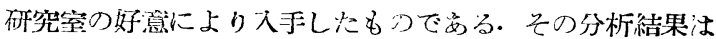
Table 1 に示した（たがし $\mathrm{O}_{2}$ 拉よび $\mathrm{N}_{2}$ の定量は行つ

Table 1 The result of chemical analysis of specimen.

\begin{tabular}{c|c|c|c|c|c}
\hline $\mathrm{C}$ & $\mathrm{W}$ & $\mathrm{Fe}$ & $\mathrm{Si}$ & $\mathrm{Cl}$ & $\mathrm{Mg}$ \\
\hline 0.034 & 0.008 & 0.053 & 0.016 & 0.010 & - \\
\hline
\end{tabular}

つていない).試料つ大いさ住 $10 \times 6 \times 0.5 \mathrm{~mm}^{3}$ である. 各種藥品に浸清した後, 試料を流水, メタノール, エーテ ルの㴿で洗谋し，彰燥した空氣で乾かした。 


\section{IH. 蠳 驗 紹 果}

\section{1. $\mathrm{HF}, \mathrm{HCl}, \mathrm{H}_{2} \mathrm{SO}_{4}$ および $\mathrm{H}_{3} \mathrm{PO}_{4}$ による简蝕}

腐蝕試驗老行う際鼠初の試料表面の狀熊によつて腐蝕過 程が影響されることも考えられるので，まず Tiのみの廹折 像を與えるような表面它得ることが必要である。このため

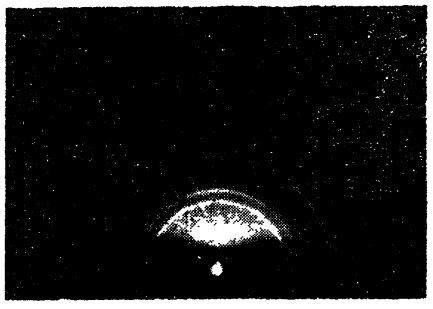

Photo. 1 Diffraction pattern of $\mathrm{TiH}_{2}$ produced on $\mathrm{Ti}$ by immersion in boiling conc. $\mathrm{HCl}$

に壓延面を弗酒夋，監 酸，硫酸などで歷蝕 し，その表面の廹折 像を撮影してはた (Photo. 1).

(a) 濃弗酸中に數 秒乃至 1 分間常溫で 浸漬すると激しく腐 蝕されて粗い結晶粒 がみえるようになる

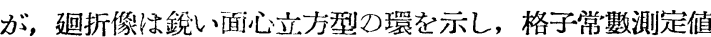
は場合により $a=4.38 \sim 4.42$ の の間の值を示す. その他 しばしば面間隔. 1,74A の極めて弱い環も現われるが，こ れは Ti の迴折環であろちと思われる。

(b) 濃鍳酸中に常溫で約 17 時間浸漬した試料表面は少 し黑ずんだ色に䵇蝕されて扣り，斑點狀の面心立友型罟を 與え，沸䲲した䕃䜿酸に短時間浸漬しても同樣に銳い面心 立方型環が現われる。 また $50 \%$ 䁷酸に浸清した場合，表 面は腐蝕されて灰色になり，迴折像は同じく面心立方型つ

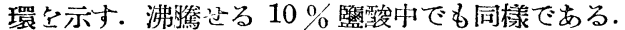

(c) 約 $45^{\circ}$ に保つた $30 \%$ 硫酸に約 30 分浸漬した場 合も銳い面心立方型環が得られ，その格子常數は $a=4.42$ ̊であつた。

(d) 沸騰せる $80 \%$ 燐酸中に極く短時間浸漬すると矢 張り面心立打型つ環が得られる.

これらの場合の格于常數測定値を Table 2 に示した.

Table 2 Observed lattice constants of facecentered-cubic type surface products.

\begin{tabular}{|c|c|c|c|}
\hline & Temperature & Immersion time & $\begin{array}{l}\text { Observed } \\
\text { lattice co- } \\
\text { nst. } a(\mathrm{~A})\end{array}$ \\
\hline & room temp. & $\begin{array}{l}\text { a few seconds } \\
17 \mathrm{hm}\end{array}$ & $\begin{array}{l}4.38 \sim 4.42 \\
4.39\end{array}$ \\
\hline & boiling & a few seconds & $4.43 \sim 4.46$ \\
\hline $50 \% \mathrm{HCl}$ & rcor & $4 \mathrm{hr}$ & 4. 40 \\
\hline & & 30 & \\
\hline 10 & & 40 & \\
\hline 30 & & 30 & \\
\hline & & few sec & \\
\hline
\end{tabular}

以上の結果をみると，(a)(b)(c) 拈よび (d) の場合何れ

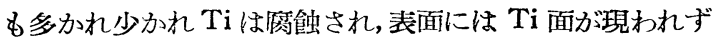

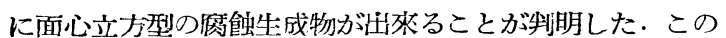
面心立方型の生成物は一應 $\mathrm{TiO}(\mathrm{NaCl}$ 型 $a=4.235 \mathrm{~A}(1))$ ではないかと考之られるが，岩䜿型格子では後に述べる如 く奇數次の反射の偶數次反射に對する相對强度が弱くなら なければならず，われわれの觀測した迴折寫導では，かよ

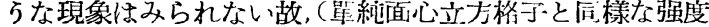
分布が見られる）たとえそれが岩監型格子党持つとして も，酸素よりもはる\%に輕い原子との化合物でなければな らぬ. 加よなことからこの生成物は Hägg(5)が Ti と水 素を反應させた際，X 線的研究から碓めた $\beta$-相に计當す るように思われる. Hägg によれば 50〜66.7 at 分 $\mathrm{H}_{2}$ を 吸收した $\beta$-相は格子常數 $a=4.397 \sim 4.460 \AA$ の间心立. 才型構造を有し $66.7 \% \mathrm{H}_{2}$ を含む埸合に完全な $\mathrm{CaF}_{2}$ 型 格于となり $\left(\mathrm{TiH}_{2}\right)$ ，水素含有量がそれ以下の旉合には水

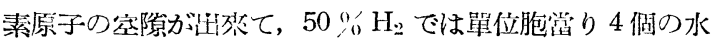
素原子が拢けた型（た心゙し ZnS 型にはならぬ）になるこ とが示されているわれわれの得た生成物はこれに䅦筫す るものと考学られる.すなおち䢙折に當つては水素原つは ほとんど影響を持たず Ti 原子のみによる迴折係が示され らのである，上記の酸で腐蝕した埸合には Ti 表网磨が㷴 蝕液帅の水素と反應して $\mathrm{TiH}_{2}$ が生成されるのですろう.

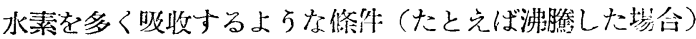
の下でな明らかに格子管數も大きくなつている。

Gulbransen 等(6)心 $\mathrm{Ti}$ と $\mathrm{O}_{2}, \mathrm{~N}_{2}$ 扔よび $\mathrm{H}_{2}$ との反應 の kinetics を研究しているぶ， $\mathrm{H}_{2}$ を吸收させた試料を 電子迴折的に謂べてを $\mathrm{H}_{2}$ との反應告城物の迴折像は得ら れず, 從つてこれらは Ti の闪部に溶けこんでいると考之

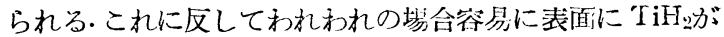
形成されることは畞味深い，さらに彼等の結果によれば， ガス反應によつて Tiに吸收された $\mathrm{H}_{2}$ は廝空中 $\left(10^{-6} \mathrm{~mm}\right.$

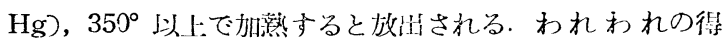
た $\mathrm{TiH}_{2}$ が果して不安定になつて分解なるか否かを檢する

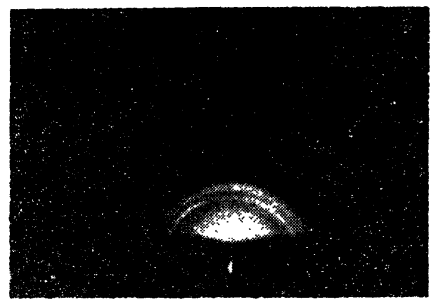

photc. 2 Diffraction pattern obtained from surface $500^{\circ}$ for 3 hr. after immersion in boiling conc. $\mathrm{HCl}$. $\mathrm{Ti}+\mathrm{TiC}$ (NaCl-type, $a=4.29 \mathrm{~A}$ ) heated in vacuum at
ために，上記の如く處 理した試料を可空中 $450^{\circ}$ 以上. で敗時閐加 熱した。その結果得ら れる迴折像は Photo. 2,3(Table 3) に示与 如く銃い環加ら成り， 加熱前に比し崉の樣子 が一戀する・すなかち $450,500^{\circ}$ で涼 Ti 環 特よび格厅常数 $a=$ $4.29 \sim 4.30 \mathrm{~A}$ の岩覧 型格子による環が現われ，600，800 で加熱すると Ti の

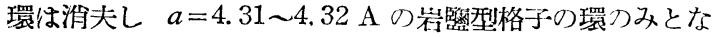
る. 岩覧型格子を有する $\mathrm{Ti}$ 化合物の中で考えられるのは $\mathrm{TiO}$ ，TiN 特よび TiC でその格子瑺數はそれぞれ 4.235， 4.235 扣上び $4.319 \mathrm{~A}^{(1)}$ である。 これらとわれわれの得た 結果とを比較すると，格于常数が注とんど等しいことから

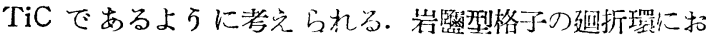

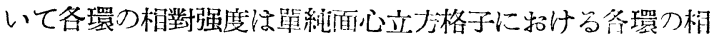

(5) G. Hägg, Z. Phys. Chem. B-11 (1930), 433.

(6) E. A. Gulbransen and K. F. Andrew, J.Metals, 1 (1949); A. I. M. E. Metals Trans., 185, 741. 
對强度と樣子が㟟なる.すなわち奇數光の絧本面からの反 射强度が單綎面心立方型の歾合に比して小さくなるのが特 徵である. その强忘を比較するために

$$
I=k \frac{\left.S\right|^{2}}{\sin \angle \theta}-\frac{p}{\theta} \approx k \frac{p}{\theta^{2}}|S|^{2}
$$

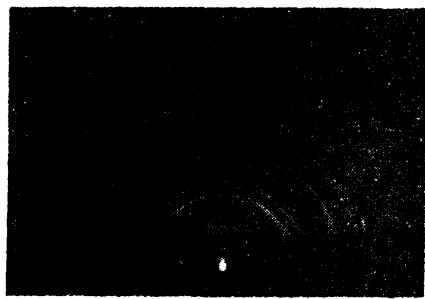

Photo. 3 Diffraction pattern obtained from surface heated in vacuum at $800^{\circ}$ for $2 \mathrm{hr}$ after immersion in $50 \%$ $\mathrm{HCl}$.

$\mathrm{TiC}(\mathrm{NaCl}$-type, $a=4.31 \mathrm{~A}$ )

$[(311) /(222)] * * * *$

Tabel 3 Observed lattice spacings from surface heated in vacuum at $500^{\circ}$ for $3 \mathrm{hr}$ after immersion in boiling conc. $\mathrm{HCl}$.

\begin{tabular}{l|c|c|c}
\hline$d(\AA)$ & $I$ (obs.) & $h k, l(\mathrm{Ti})$ & $\begin{array}{c}h k l(1 \mathrm{iC}, \\
\text { Na Cl-type) }\end{array}$ \\
\hline 2.55 & m.st. & 10.0 & $\overline{111}$ \\
2.47 & m.st. & - & - \\
2.26 & st. & 10.1 & 200 \\
2.14 & st. & $-\overline{10.2}$ & - \\
1.741 & w. & - & - \\
1.522 & m. st. & 11.0 & 220 \\
1.488 & w. & 10.3 & - \\
1.352 & v.w. & - & 311 \\
1.302 & v.w. & 20.1 & 222 \\
1.242 & v.w. & & $a$ (mean) \\
& & & $=4.29 \mathrm{~A}$ \\
\hline
\end{tabular}

以上の結果加ら真空加熱によつて $\mathrm{TiH}_{2}$ が分解して $\mathrm{H}^{2}$ が放出され，表面にTiが現われることは電于迴折的に證明

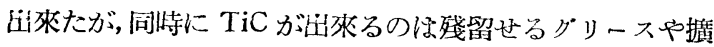
散ボンプ油などの烝氣がTi と反應した結果と考えられる。

\section{2. $\mathrm{HNO}_{3}$ による简蝕(常溫)}

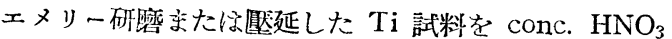
*** 奇數次の反射に對して $|S|=4\left(E_{\mathrm{Ti}}-E_{0}\right)$, 偶數次の反 射に對して $|S|=4\left(E_{\mathrm{Ti}}+E_{0}\right)$ であり，こっで $E=\frac{8 \pi^{2} m e^{2}}{h^{2}}$ $\frac{Z-f(s)}{s^{2}}$ は電子線に對する原子散亂因子である,だ゙し

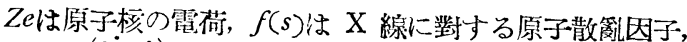
$s=4 \pi\left(\frac{\sin \theta}{\lambda}\right)$ である。

**** TiC に招ける $\mathrm{Ti}$ 原子と C 原子の結合はイオン結 合と考えるよりも， TiC の種ふの性質からみて主しろ金 屬的結合に近いと考える放没當であるようであるが， こ

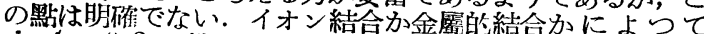
$\sin \theta / \lambda<0.2$ の筙圍では $E$ が變るが, $\sin \theta / \lambda$ の大なる所 ではほとんど影響されないので Table 4 では Ti++ と (neut.)に對する $f(s)$ [W. H. Bragg and W. L. Bragg, The Crystalline State, Vol. I (1939), Appendix IV] 用いて計算し（200）-翼より高炏の反射で比較した。

(7) J. D. Hanawalt, H. W. Rinn and L.K. Frevel, Ind. Eng. Chem. Anal. Ed.. 10 (1938), 457.

または $50 \% \mathrm{HNO}_{3}$ 中に長時間(4〜10 日) 常溫で浸漬す ると表面の迴折僬はほとんど Ti の迴折環つみを示す.

Table 4 Relative intensities of diffraction rings due to $\mathrm{TiC}(\mathrm{NaCl}$-type $)$.

\begin{tabular}{c|c|c}
\hline$h k l$ & $I$ (calcu. & $I$ (obs.) \\
\hline 200 & 100 & st. \\
220 & 42 & st. \\
311 & 9 & m. st. \\
222 & 11 & m. st. \\
400 & 4 & v. w. \\
331 & 3 & v. w. \\
420 & 9 & m. st. \\
422 & 5 & w. \\
\hline
\end{tabular}

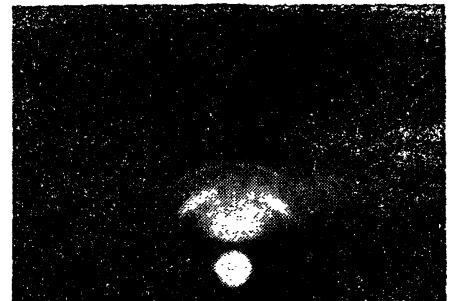

Photo. 4 Diffraction pattern of $\mathrm{Ti}$ obtained from surface immersed in conc. $\mathrm{HNO}_{3}$ for10days at room temperature.
(1)に記した方法 で真空加熱过る Ti 执よびTiCの 迴折袈走示寸試料 を浸漬した場合も 同樣であり, $\mathrm{TiC}$ の環は消失する。

\section{Photo. 4, Table} 5 に觀湘結果の一 例を示した。たが し內側に Ti 以外

Table 5 Observed lattice spacings from surface immersed in conc. $\mathrm{HNO}_{3}$ for $100 \mathrm{hr}$ at room temperature.

\begin{tabular}{c|c|c|c|c}
\hline \hline \multirow{2}{*}{$(h k, l)$} & \multicolumn{2}{|c|}{$\begin{array}{l}\text { Electron diffraction } \\
\text { data (obs.) }\end{array}$} & \multicolumn{2}{|c}{$\begin{array}{c}\text { X-ray diffraction } \\
\text { data for Ti(7) }\end{array}$} \\
\cline { 2 - 5 } & $d$ (A) & $I$ & $d(\AA)$ & $I$ \\
\hline 10.0 & 2.54 & st. & 2.54 & 0.27 \\
00.2 & 2.37 & st. & 2.34 & 0.20 \\
10.1 & 2.24 & v. st. & 2.23 & 1.00 \\
10.2 & 1.72 & m. st. & 1.72 & 0.13 \\
11.0 & 1.471 & m. st. & 1.470 & 0.13 \\
10.3 & 1.328 & st. & 1.330 & 0.13 \\
20.0 & 1.268 & v. w. & 1.275 & 0.01 \\
11.2 & 1.239 & m.st. & 1.248 & 0.11 \\
10.4 & 1.071 & w. & - & - \\
\hline
\end{tabular}

の弱いぼけた環が 1〜2 本現われることもおる $(d \approx 4.2$, 3. 3, 1.67 A).

われわれはこの方法によつて得た表面を試料の计登狀熊 として用いた・すなわちすべて鹰蝕試驗前に試料を conc, $\mathrm{HNO}_{3}$ 中に浸清し， $\mathrm{Ti}$ のみの迴折環が現われることを碓 認した後に腐蝕試驗を行つた. 以下主として不働態を作る 酸類について實驗它行つた。

\section{3. $\mathrm{HNO}_{3}$ による簿鲉(沸騰)}

$50 \% \mathrm{HNO}_{3}$ 中に試料を入れて約 1 時間沸騰させると 表面は淡褐色に變化し, その迴折像は少に、添けた Debye 一環を示す. その面間隔测定結果および肉眼觀察强度を Table 6 に示したが大體 $\mathrm{TiO}_{2}$ (anatase; tetragonal, $\left.a=3.776 \mathrm{~A}, c=9.486 \mathrm{~A}^{(1)}\right)$ として說明出東る.たがし この場合 anatase の最內側の環 $(d=3.52 \mathrm{~A})$ の測定値 が少し大きく 3.56〜3.58 A であつた。また夙にはTiに 屬する弱い環力゙殘つていることも㐫，この焉實拉よび 


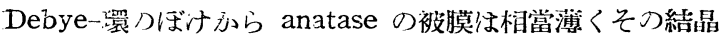
rutile による環つみとなる。こ札らの緯果を Fig. 1 に圖 は微細である己考えられる. conc, $\mathrm{HNO}_{3}$ 中で 2 時間沸鹩 式的に示し，廻折寫買つ一例定 Photo. 7 に示した。

Table 6 Observed lattice spacings of surface films produced by immersion in $\mathrm{HNO}_{3}$ and aqua regia at various conditions.

\begin{tabular}{|c|c|c|c|c|c|c|c|}
\hline \multicolumn{2}{|c|}{$50 \% \mathrm{HNO}_{3} 60 \mathrm{~min} . \mathrm{bcil}$} & \multicolumn{2}{|c|}{ conc. $\mathrm{HNO}_{3} 2$ hr. boil } & \multicolumn{2}{|c|}{ aqua regia $1.5 \mathrm{hr}$. boil. } & \multirow{2}{*}{$\begin{array}{l}\mathrm{TiO}_{2} \text { (anatase) } \\
\text { tetragonal } a= \\
\text { 3. } 776 \AA \text { A, } c=9.486 \mathrm{~A} \\
d(\AA)(7)\end{array}$} & \multirow{2}{*}{$\begin{array}{l}\text { Ti hexagonal } a= \\
2.92 \AA, c=4.67 \AA \\
d(\AA)(7)\end{array}$} \\
\hline$d(\AA)$ & $I$ & $d(\mathrm{~A})$ & $I$ & $d(\AA)$ & $I$ & & \\
\hline 3.56 & v. st. & 3.52 & v. st. & 3.56 & v. st. & 3.52 & $\overline{-}$ \\
\hline $2 \overline{40}$ & m. st. & $2 \overline{38}$ & m. st. diff. & $\begin{array}{l}2.57 \\
2.40\end{array}$ & $\begin{array}{l}\text { m. st. } \\
\text { st. }\end{array}$ & $\overline{2.37}$ & $\begin{array}{l}2.54 \\
2.34\end{array}$ \\
\hline-1 & - & 2.0 & - & 2.24 & m. st. & - & 2.23 \\
\hline 1.90 & m. st. & 1.89 & m. st. & 1.92 & m. st. & 1.88 & $\cdots$ \\
\hline 1.69 & st. & 1. 69 & st. diff. & 1.71 & v. st. diff. & 1. 70 & 1. 72 \\
\hline 1.492 & m. st. & 1. 486 & m. st. & 1. 490 & m. st. & 1.66 & 1. 470 \\
\hline- & - & -.- & - & 1. 376 & w. & 1. 48 & - \\
\hline 1. 359 & $\mathrm{w}$ & 1. 353 & m. st. & 1. 351 & m. st. & 1. 362 & 1.330 \\
\hline 1.269 & $\mathrm{w}$ & 1.268 & m. st. & 1.272 & m. st. & 1.335 & 1. 275 \\
\hline 1. 172 & v. w & 1. 165 & w & 1.180 & w. & 1. 262 & 1.248 \\
\hline \multicolumn{2}{|c|}{$\mathrm{TiO}_{2}$ (anatase) } & \multicolumn{2}{|c|}{$\mathrm{TiO}_{2}$ (anatase) } & \multicolumn{2}{|c|}{$\mathrm{Ti}+\mathrm{TiO}_{2}$ (anatise) } & & \\
\hline
\end{tabular}

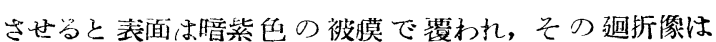

Table 6, Photo. 5 に示す如く anatase の環によく一致

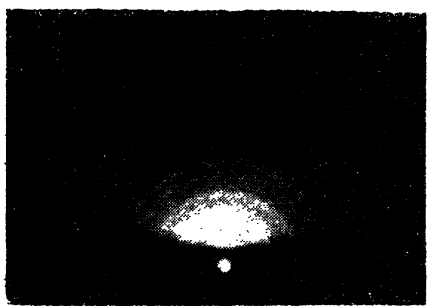

Photo. 5 Diffraction pattern of $\mathrm{Ti} \mathrm{D}_{2}$ (anatase) produced on Ti suriace by immersion in boiling conc. $\mathrm{HNO}_{3}$ for $2 \mathrm{hr}$.

ナる.この表百它再 び aこtive にするた め，沸驇やる conะ。 $\mathrm{HCl}$ 中に約 10 砂間 浸清与ると迴折激は anatase の環（たよ゙ し帠、内測刀環は $d$ 二 $3.57 \AA$ ) 扣よび弱、 Ti の猿走示し, 20 秒後には面心立与型 $\mathrm{TiH}_{2}$ の環に戀化 งฺ.

\section{4. 王水による简蝕}

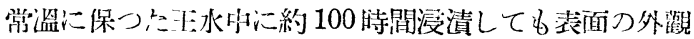
沵何等變化せず，廻折像保最初》 Ti の環と anatase と

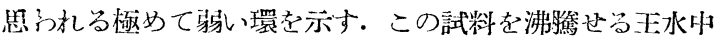
に約 30 分没漬した兟合も袁面の外觀住何等變化しない が，迴折像に浨 Ti の環と anatase の環（たがし最内測

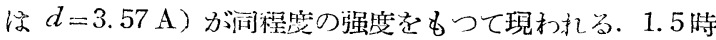

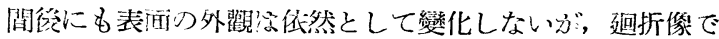
は anatase の睘の强度が Ti の環の强度よりも大きくな る (Table 6, Photo. 6).

\section{5. $10 \% \mathrm{CrO}_{3}$ 冰溶液による符蝕}

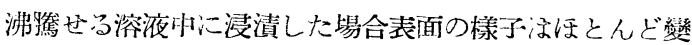

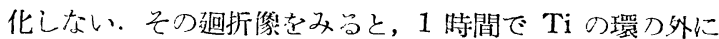
$d=3.3 \AA$ 扰よで $1.70 \AA$ の環が現われ，4時間後には $\mathrm{Ti}$ の環つ外に比校的强い $\mathrm{TiO}_{2}$ (anatase, たがし最闪側 の環惁 $d=3.57 \AA$ ) による環招よび弱い rutile 型力 $\mathrm{TiO}_{2}$ (tetragonal, $a=4.492 \mathrm{~A}, c=2.893 \mathrm{~A}$ )(1)による環 が現われる. 10 時間浸清後つ迴折化では，Ti の環生消え $て$ anatase (この場合晨闪測つ環待 $d=3.52$ A ) 和よび

\section{6. $\mathrm{NaCl}$ 鵤和水溶液による符蝕}

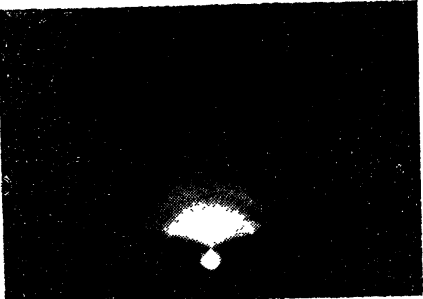

Photo. 6 Diffraction pattern of $\mathrm{TiO}_{2}$ (anatase)produced on Ti suriace by immersion in boiling aqua regia for 1. 5 hr. Diffraction rings due to initial $\mathrm{Ti}$ are visible.

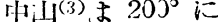
保つ $\mathrm{NaCl}$ 水溶液 小で約30分加熱した 際㻻西儿 rutile $の$ 被膜决生成されるこ と点捗告している。

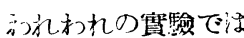
約 $100^{\circ}$ に保つた $\mathrm{NaCl}$ 水溶液中に長 㭙閶(10時間まで)

漫清したところ，試 料つ外観は無論變

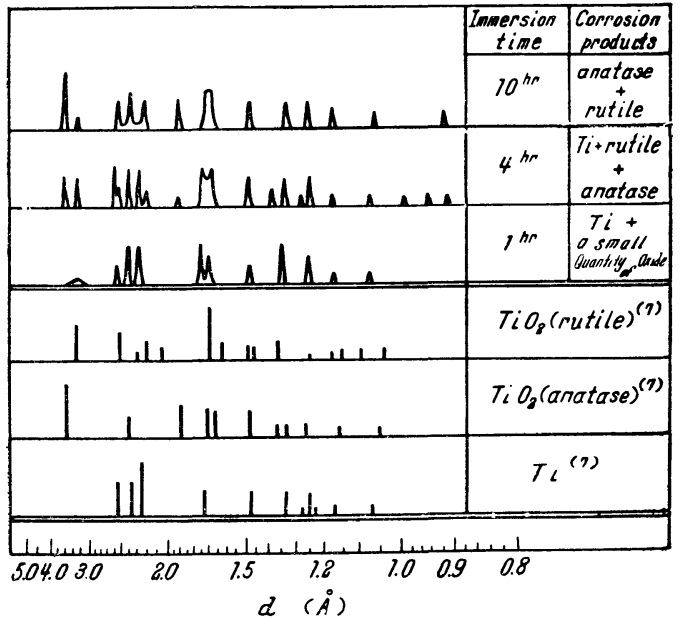

Fig. 1 Diffraction pattern diagrams obtained from surfaces immersed in boiling $10 \%$ $\mathrm{CrO}_{3}$-solution. (Height of curves should be uncierstood to represent relativa intensities within a single diagram only.) Patterns of three referred substances are also shown. 
化しないが, 30 分後かっら $\mathrm{Ti}$ の斑默狀迴折環の外に $d=$ $1.69 \mathrm{~A}$ の弱いDebye 環が現われ，10 時間後にはさら

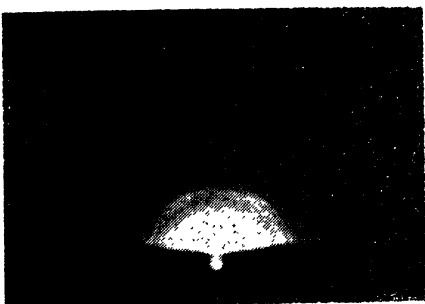

Photo. 7 Diffraction pattern of $\mathrm{TiO}_{2}$ (anatase and rutile) produced on $\mathrm{Ti}$ surface by immer: ion in boiling $10 \% 6 \mathrm{CrO}_{3}$-solution for $10 \mathrm{hr}$. Table 7 Observed lattice spacings of surface
film produced by immersion in boiling $10^{\circ} \mathrm{FeCl}_{3}$-solution for $1 \mathrm{hr}$.

\begin{tabular}{c|c|c|c}
\hline$d(\AA)$ & $I$ & $d(\AA)$ & $I$ \\
\hline 7.6 & v.st. & 1.64 & v. st. \\
5.3 & m.st. & 1.50 & st. \\
3.35 & v.st. & 1.444 & st. \\
2.63 & st. & 1.374 & m. st. \\
2.54 & v. st. & 1.303 & w \\
2.38 & m. st. & 1.223 & w \\
2.28 & v. st. & 1.144 & w \\
2.10 & m. st. & 1.059 & w \\
1.95 & st. & 1.018 & w \\
1.74 & m. st. & & \\
\hline
\end{tabular}

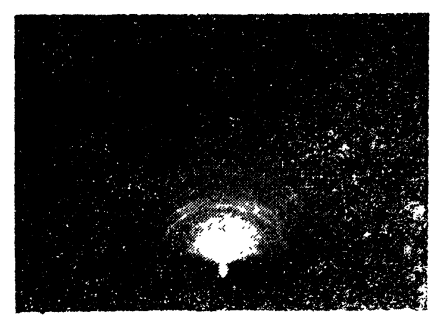

Photo. 8 Diffraction pattern of unknown substance produced on $\mathrm{Ti}$ surface by immersion in boiling $10 \% \mathrm{Fe} \mathrm{Cl}_{3}-\mathrm{silution}$ for $20 \mathrm{~min}$

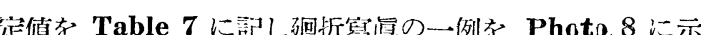
した.こつ迴折侄を全部說明讪㷊るような $\mathrm{Ti}$ 化合物蚛現 在のところ見當らず，表面告成物の性質を明らかにするに
はさらに詳細な研究が必要である。

\section{IV. 結果に對する考察}

以上が現在をでに得られた實驗結果でするが，これを Ti の簿饉試驗の結果と比较してみ; よう. $\mathrm{HF}, \mathrm{HCl}, \mathrm{H}_{2} \mathrm{SO}_{4}$ 牤よび $\mathrm{H}_{3} \mathrm{PO}_{4}$ が $\mathrm{Ti}$ に對して多かれ少少孔影響をおよぼ

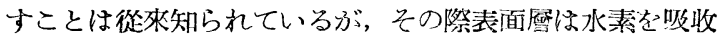
して $\mathrm{TiH}_{2}$ になることが電于獧折的こ確ふめられた。これ に反して常溫に保つた $\mathrm{HNO}_{3}$ 少に 4 10 日間位浸漬し た場合に Ti の夕の迴折像が得られるのは汒目すべきこと である. さらに沸騰せる $\mathrm{HNO}_{3}$, 王水, $10 \% \mathrm{CrO}_{3}$ 水溶 液, $\mathrm{NaCl}$ 水溶液中に浸漬した場合重量娍がなく涌蝕性は 極めて優秀で交るが，電于迴折的には conc. $\mathrm{HNO}_{3}$ の埸 合表面の變色狀態ならびに Ti の環が現われないこと办 ら，表面には比較的厚い anatase の被膜分汧成され，そ の他の場会相當長時間浸漬しても Ti の環が殘つていらこ とから極めて溥い繥密な酸化被膜 ( $\mathrm{TiO}_{2}$, anataseぬたは rutile）が形成されて，何れも不動態になることが少明し た. $10 \% \mathrm{FeCl}_{3}$ 水溶液中でも表面は溥い被膜で覆わ扎不 働態になることは明らかである。

TiO., には anatase-rutile-brookite (orthorhombic) の變態が存在し，その變熊溫度は $T_{\text {anat } \rightarrow \text { rutile }}=915^{\circ}$, $T_{\text {rutile } \rightarrow \text { brook }}=1300^{\circ}$ といわれている. Ti の酸化物としては この外に $\mathrm{Ti}_{2} \mathrm{O}_{3}$ (rhombohedral)， $\mathrm{TiO}(\mathrm{NaCl}$ 型)などが

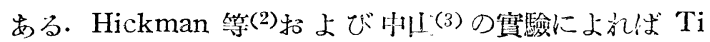
を宾氣中で酸化させた際 rutile型つ $\mathrm{TiO}_{2}$ が朵成される ことが報ぜられているが，われわれの筞蝕試驗に捣いては rutile は谷易に形成されず，比較的低溫度で安定な anatase が出來やすい. し方も anatase が计來る最初つ 狀態では面間隔 $d=3.52 \mathrm{~A}$ となるべき環㤂3.56〜3.58 A

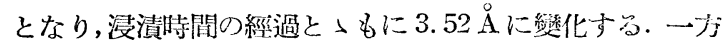
Ehrlich(8)の X 線牨研究に上れば Ti 酸化物の迴折像は その組成により相賞樣子が變化することが淮められてい る. われわれの場合にも anatase が生成される途中の段 階に特いて闻間隔が〜3.57 A $3.52 \mathrm{~A}$ の經過をたどる愿 因があるのではないかと考えられる。

終りに臨み本研究のために試料を快く分與されかつ有益 な助言を賜つた東北大學金屬材料研究所大日ち教授ならび に竹內氏に深く感謝する.

(8) P. Ehrlich, Z. Elektrochem., 45 (1939), 362. 